Revue interdisciplinaire des études canadiennes en

France

$72 \mid 2012$

Au-delà des frontières, jusqu'où va le Canada ?

\title{
In Memoriam Régis Marchiaro (1947-2012)
}

\section{Hélène Harter}

\section{OpenEdition}

Journals

Édition électronique

URL : http://journals.openedition.org/eccs/334

DOI : $10.4000 /$ eccs.334

ISSN : 2429-4667

Éditeur

Association française des études canadiennes (AFEC)

Édition imprimée

Date de publication : 1 juin 2012

Pagination : 7-8

ISSN : 0153-1700

Référence électronique

Hélène Harter, «In Memoriam Régis Marchiaro (1947-2012) », Études canadiennes / Canadian Studies

[En ligne], 72 | 2012, mis en ligne le 01 juin 2014, consulté le 15 septembre 2020. URL : http://

journals.openedition.org/eccs/334 


\section{In Memoriam Régis MARCHIARO (1947-2012)}

C'est avec une profonde stupéfaction que nous avons appris le 17 octobre 2012 la nouvelle du décès de Régis Marchiaro qui venait de nous quitter dans la nuit. Le premier choc passé, plusieurs images viennent à l'esprit : l'enthousiasme communicatif de Régis, les nouvelles idées qu'il apportait à nos réunions de directeurs de centre d'études canadiennes et du conseil d'administration de l'AFEC, son engagement pour les études canadiennes et en particulier pour la jeunesse dont il faisait une priorité. Comment oublier le savoir-faire, l'énergie et la bonne humeur qu'il a mis au service du $39^{\mathrm{e}}$ colloque de l'AFEC qu'il a organisé à Montpellier en juin 2011 sur le thème «Au-delà des frontières : jusqu'où va le Canada ? »; faisant de cet événement un succès indéniable qui restera longtemps dans les esprits. Sa disparition inattendue est d'autant plus poignante qu'elle intervient au moment même où il achevait l'édition des Actes de ce colloque qui composent ce volume.

Régis, nous le savons tous, était résolument attaché à sa ville qu'il nous a fait découvrir avec passion. C'est à Montpellier qu'il a fait ses études, qu'il a soutenu ses deux thèses de doctorat puis qu'il a enseigné pendant trente ans à la faculté de droit public de l'université Montpellier I. Tout au long de ces années, il a été un professeur profondément investi dans les activités du Centre de Recherche et d'Étude Administrative de Montpellier (CREAM) où il a notamment encadré plusieurs thèses de doctorat. Son sens du collectif l'a également conduit à siéger pendant quinze ans au conseil scientifique de son université (1989-1994) puis à être membre du cabinet du président (1994-1999) avant de devenir directeur du Service Universitaire d'Information et d'Orientation et d'insertion professionnelle (19942000). Il a également dirigé plusieurs DESS et masters professionnels à Montpellier I, notamment celui sur la Gestion des mers et des Littoraux, alliant enseignement universitaire et travail sur le terrain avec autant de bonheur.

Sa fierté pour ses attaches montpelliéraines n'a jamais exclu un véritable intérêt pour l'international. Ses sujets de recherche en témoignent. Après une thèse de troisième cycle de droit public international sur Les relations interétatiques en Amérique Latine en 1979, il soutient en 1990 un doctorat d'État en droit public sur La gestion du patrimoine hydrologique international. Régis était un juriste reconnu sur les questions d'environnement et de développement durable ainsi que sur la gestion des risques et les questions de sécurité. Son expertise l'a conduit à participer à de nombreux projets internationaux. Il a été ainsi responsable d'un groupe de réflexion sur «Le droit international et les peuples autochtones » en collaboration avec les universités de Western Ontario et de l'UNAM au Mexique. Pendant dix ans, il a été membre du Comité français de la Décennie Internationale pour la prévention des Catastrophes Naturelles des Nations Unies (DIPCN). Il a été également pendant plus de quinze ans secrétaire général du Centre d'Études et de Recherche Internationale de Montpellier (CERIM). Cette projection internationale l'a naturellement conduit à être professeur invité dans plusieurs pays, en Roumanie, en Azerbaïdjan, en Russie et bien sûr au Canada. 


\section{Hélène HARTER}

À partir des années 1990, Régis consacre en effet de plus en plus de son temps à l'étude du Canada tout en menant des recherches sur le droit et la construction européenne; faisant ainsi mieux connaître l'Europe aux juristes canadiens et le Canada à ses collègues français. Ses collaborations avec les universités canadiennes ont été nombreuses : il a participé à de nombreux colloques à l'université Laval, a été professeur invité aux universités de Western Ontario et d'Ottawa, a collaboré à l'université virtuelle du CEPEPOSA (Canadian Europe, Policy Options for Sustenable Agriculture) mise en place notamment par les universités d'Ottawa et de Saskatoon. Dans son université même, il a été responsable des échanges avec l'université de Western Ontario et d'Ottawa. Il a également consacré beaucoup de son dynamisme à la vie associative. Dès 1987, il est secrétaire de l'association France-Canada pour la région de Montpellier. En 1992, il devient trésorier du Centre d'Etudes canadiennes des Universités de Montpellier, le CECAM. Il était donc tout naturel que ses collègues le choisissent pour prendre la direction de ce centre en 2003 lors du départ à la retraite de JeanPhilippe Colson.

Dans un paysage universitaire en pleine reconstruction, Régis a beaucoup travaillé au rayonnement de cette structure pluridisciplinaire qui réunit les universités de Montpellier I, Montpellier II et Montpellier III. La tâche n'a pas été toujours simple mais l'optimisme de Régis a porté ses fruits. Le colloque de l'AFEC qu'il a organisé de main de maître en juin 2011 est là pour nous le rappeler. Cette rencontre internationale a témoigné au-delà d'une belle réussite scientifique des nombreuses facettes de la personnalité de Régis : son intérêt profond pour le Canada qui n'excluait pas un regard distancé et critique, le goût pour la pluridisciplinarité, le souci de la relève, la curiosité pour les nouvelles technologies qui permettent de valoriser les travaux des chercheurs et de les faire connaître audelà des cercles académiques, la volonté de faire se rencontrer les universitaires, les praticiens et la société civile, sans oublier un profond sens de la convivialité et une capacité à construire des liens amicaux bien au-delà des simples relations professionnelles ; autant de valeurs dont notre association est également porteuse et qui expliquent pourquoi Régis était si apprécié à l'AFEC.

Il était donc naturel que nous dédiions ce volume 72 à Régis Marchiaro. En le lisant, vous retrouvez, j'en suis sûre, beaucoup de sa personnalité et de ses centres d'intérêt. C'est un des héritages qu'il nous laissera.

Hélène Harter

Professeur des universités en histoire contemporaine Présidente de l'AFEC

4 novembre 2012 